\title{
REPERTÓRIOS DE AÇÃO COLETIVA E CONFRONTOS POLÍTICOS: ENTREVISTA COM SIDNEY TARROW
}

Nas duas últimas décadas, os estudos da ação coletiva e dos movimentos sociais vêm passando por transformações significativas nas ciências sociais. Problemas persistentes na teoria social estão sendo revistos e novas questões de ordem empírica, teórica e metodológica vêm sendo levantadas. No Brasil, a dominância das teorias dos novos movimentos sociais, nos anos 1970 e 1980, e de seu desdobramento, a teoria da sociedade civil, desde os anos 1990, começam a ser contrabalançadas pelas teorias norte-americanas da ação coletiva, dos movimentos sociais e do confronto político.

Embora não sejam homogêneas, as teorias norte-americanas, sobretudo a teoria do confronto político, sob liderança de Charles Tilly e Sidney Tarrow, vêm redesenhando os estudos das dinâmicas de mobilização, negociação e confronto das ações coletivas, assim como vêm contribuindo decisivamente para revigorar umas das áreas mais tradicionais das ciências sociais, a sociologia política, forçando inclusive redefinições de algumas das suas categorias aparentemente mais estáveis, caso do conceito de conflito social. Mais ainda, ao conectar história e teoria, estas abordagens têm enfrentado algumas das mais profundas antinomias da teoria social, como a dicotomia "ação"/“estrutura", apresentando, portanto, significados para as ciências sociais em geral. Ao valorizar, de um lado, a capacidade de agência e a criatividade dos indivíduos em suas mobilizações, mas sem descuidar, de outro, dos constrangimentos históricos e políticos que limitam as oportunidades da ação coletiva, novas perspectivas são criadas para o enfrentamento daquela e de outras dualidades das ciências sociais. Este o significado sociológico mais amplo, por exemplo, do conceito de "repertório confrontacional", de Charles Tilly, que compreende o conjunto de formas de ação política surgidas em meio a conflitos numa dada época e que a partir de então fica à disposição dos atores sociais.

Charles Tilly e Sidney Tarrow são, certamente, dois dos mais importantes teóricos desse movimento intenso de renovação da sociologia política, ainda em curso. Nesta entrevista, gentilmente concedida, Sidney Tarrow, Professor Emérito da cátedra Maxwell M. Upson da Universidade de Cornell, aborda 
estas e outras questões desenvolvidas em seus trabalhos, nos de Charles Tilly e nos que ambos desenvolveram juntos. Sociologia \& Antropologia busca, deste modo, somar as iniciativas de divulgação dessa importante vertente sociológica contemporânea ainda pouco explorada no Brasil e na América Latina em geral. ${ }^{1} \mathrm{E}$ também presta, junto com o Professor Tarrow, a quem agradecemos, sua homenagem ao trabalho pioneiro de Charles Tilly, falecido em 2008. ${ }^{2} \mathrm{~A}$ obra de Tilly é, numa palavra, incontornável para aqueles que estamos desafiados a compreender a dinâmica histórica e as inovações nos protestos e confrontos políticos do passado e no mundo contemporâneo.

Angela Alonso \& André Botelho. Desde a publicação do seu primeiro livro sobre a Itália (Tarrow, 1967) sua pesquisa tem se concentrado em mobilizações sociais e sua relação com o estado. Como foi que você veio a se dedicar a esse assunto? Sidney Tarrow. Eu estudei em Berkeley durante o Movimento pela Liberdade de Expressão (Free Speech Movement). Apesar de não ter participado como ativista, não pude ignorar o que se passava em frente à minha janela. Meu trabalho na Itália se concentrara principalmente no Partido Comunista e seus erros cometidos no Sul da Itália. Quando comecei a escrever sobre o assunto para minha tese de doutorado em Berkeley, descobri que a literatura sobre partidos políticos não era de grande utilidade e vim a entender que o verdadeiro fracasso do partido fora sua incapacidade de conquistar a militância dos próprios camponeses que estava tentando organizar. Isso se devia em parte aos líderes do partido, que, em sua maioria, eram intelectuais de origem burguesa - aquilo que Gramsci chamou de "intelectuais tradicionais" -, mas o motivo principal era a disjunção que existia entre as metas nacionais do partido (a assim chamada "via italiana al socialismo") e as energias insurgentes dos camponeses. Desde então, sempre estive interessado nas relações entre partidos e movimentos. Isso me fez seguir uma trilha diferente daquela seguida pelo teórico dos movimentos sociais então dominantes na América Latina, Alain Touraine, que não se interessava por partidos e desdenhava o problema da organização no estudo dos movimentos sociais. Foi apenas nos últimos anos que os estudiosos latino-americanos de movimentos sociais voltaram sua atenção para os tipos de processos políticos com os quais eu venho lidando.

A.A. \& A.B. Seu trabalho esteve intimamente ligado ao trabalho de Charles Tilly pelo menos durante a última década. Você pode nos contar um pouco sobre essa parceria intelectual?

S.T. Na verdade, conheci Tilly quando comecei a lecionar, na década de 1960, e ele veio fazer uma palestra sobre a história da revolução na França. Encontrei- o novamente quando ele estava editando seu livro sobre a formação dos estados nacionais na Europa ocidental (The formation of national states in Western Europe), nos anos 1970. Na época, eu achava que ele era um especialista em 
formação de estados, e é assim que a maioria dos cientistas políticos norte-americanos o vê ainda hoje. Apenas quando decidi fazer uma análise histórica baseada na compilação de eventos dos movimentos de protesto italianos (Democracy and disorder, 1989), foi que descobri que ele tinha uma outra vida como estudioso de movimentos sociais. Adotei partes importantes da sua metodologia para a análise de movimentos sociais a partir da compilação de eventos. Depois, nos encontramos com Doug McAdam, durante uma conferência organizada em homenagem a Tilly, em Amsterdã, e descobrimos que compartilhávamos da mesma insatisfação sobre o estado da pesquisa sobre movimentos sociais nos Estados Unidos: nós três sentíamos que a tradição dominante, apesar de se autodenominar "abordagem do processo político", havia se tornado bastante estática e ignorava os mecanismos que levam os atores a entrar em interação confrontacional. Essa foi a origem do livro Dynamics of contention (La dinámica de la contienda, em espanhol; o livro não foi traduzido para o português), que nós três escrevemos, e de Contentious politics (2006), escrito por Tilly e eu.

A.A. \& A.B. Dynamics of contention, o livro que você, Tilly e McAdam publicaram no início da década de 2000 , estabeleceu uma agenda teórica e empírica no campo das sociologias política e histórica, visando a trocar o foco do fenômeno limitado dos movimentos sociais para o fenômeno mais amplo da política confrontacional. Agora que se passou mais de uma década desde a publicação do livro, como você o avalia?

S.T. É verdade que tínhamos uma postura crítica em relação à pesquisa norte-americana por concentrar sua atenção nos movimentos, enquanto nós nos interessávamos pelo fenômeno mais geral, que viemos a chamar de "política confrontacional". Muitos dos nossos críticos acreditavam erroneamente que estávamos apenas dando um nome novo a algo que eles já estavam estudando - os movimentos sociais. Mas, na verdade, estávamos tentando estender as fronteiras da disciplina para abarcar a política confrontacional de todos os tipos. Creio que esperávamos demais dos nossos leitores americanos ao exigir que acreditassem que poderiam usar o mesmo enquadramento analítico para entender movimentos, greves, guerras civis, revoluções etc. E preciso confessar que nos precipitamos ao dizer como isso poderia ser feito. O livro foi um exercício pedagógico - sua intenção era estimular um debate, não era um trabalho de pesquisa cuidadosa. Creio que muitos dos nossos críticos norte-americanos não entenderam isso claramente. Acho que é por isso que o livro tem obtido uma resposta mais positiva na Europa e na América Latina, porque aqui sempre houve uma abordagem mais ampla na pesquisa sobre movimentos sociais do que nos Estados Unidos, e muito mais parecida com nosso conceito de "política confrontacional". 


\begin{abstract}
A.A. \& A.B. Você reescreveu pelo menos duas vezes seu livro Power in movement [publicado no Brasil como Poder em movimento], ${ }^{3}$ que se tornou um dos clássicos no campo da sociologia política. Por que você decidiu revisá-lo, em vez de escrever um livro novo - ou, pelo menos, um posfácio?
\end{abstract}

S.T. Boa pergunta, e como se sabe, perguntas boas costumam ter mais de uma resposta. A primeira resposta é a mais simples: Power in movement continuou sendo usado por professores de movimentos sociais e política confrontacional, e achei importante atualizá-lo. Minha editora, a Cambridge University Press, estava particularmente interessada em uma edição atualizada. Mas existem mais dois motivos: o primeiro é que minha própria abordagem intelectual mudou desde que escrevi o livro pela primeira vez, no início da década de 1990 (em parte, essas mudanças ocorreram devido ao meu relacionamento com Tilly e McAdam e, em parte, porque passei a me interessar por novas formas de confronto). Eu queria que o livro refletisse isso. A outra razão é que qualquer pessoa intelectualmente ativa que reveja seu trabalho de duas décadas atrás não pode estar satisfeita com aquilo que escreveu na época. Recentemente, tive a oportunidade de rever meus primeiros trabalhos sobre a Itália para uma antologia que será publicada pela Cambridge, intitulada Strangers at the gates: movements and states in contentious politics e vi que teria que reescrevê-lo completamente à luz da minha perspectiva atual sobre a política confrontacional.

A.A. \& A.B. Recentemente, em uma série de artigos e no seu livro Transnational activism, você tem lidado com as transformações sofridas pela mobilização social no contexto da globalização. Quais são os pontos de virada que você vê nas assim chamadas novas mobilizações? Ou você acha que está sendo criado um novo repertório de confrontação?

S.T. Isto é complicado. Diferente de muitos estudiosos do confronto transnacional, dentre os quais alguns como Peter Evans e Giovanni Arrighi, bem conhecidos na América Latina, eu não derivo movimentos sociais transnacionais da globalização ou do neoliberalismo. Creio que muitos movimentos transnacionais têm mais a ver com fatores políticos e culturais - os movimentos de direitos humanos, por exemplo - do que com a globalização econômica. E acho também que, embora a globalização tenha causado seus efeitos mais devastadores no Hemisfério Sul, a mobilização transnacional tem sido mais ativa no Norte. $\mathrm{O}$ que me parece ser a base para a produção de confrontação transnacional é, primeiramente, o crescimento daquilo que, em The new transnational activism, chamo de "cosmopolitismo enraizado" - a transformação cultural dos jovens - e a internacionalização, um fator institucional. Mas concordo que esses aspectos muitas vezes acompanham a globalização: veja, por exemplo, o trabalho interessante de Marisa Von Bulow, no Brasil, ou de Tamara Kay sobre o NAFTA (North American Free Trade Agreement): ambas estudam movimentos que surgem em reação ao comércio econômico livre, mas aquilo que vincula ativistas de 
países diferentes é, em ambos os casos, o processo político e o cosmopolitismo cultural. Vejo a importância da globalização como um enquadramento para a ação coletiva ou como um guarda-chuva, sob o qual uma série de reivindicações diferentes pode ser feita e os reivindicadores podem reconhecer uns aos outros.

A.A. \& A.B. Estamos vivendo uma onda de mobilizações sociais no mundo inteiro. Você acha que a "primavera árabe" pode ser entendida como um ciclo de protestos como você o definiu? Essas mobilizações, nas quais as reivindicações materiais são proeminentes, parecem se enquadrar mal numa explicação à maneira da teoria dos Novos Movimentos Sociais, você não acha? Qual seria o caminho analítico mais apropriado para entendê-los?

S.T. Não sei se estamos no auge ou no fim dessa onda de mobilizações. A primavera árabe me lembra, em muitos aspectos, o ano de 1848 na Europa, que também começou com o entusiasmo e o sucesso popular, mas que encontrou seu fim em intervenções militares e repressão. Certamente parece ser um ciclo de confronto (como o de 1848), mas apesar de sabermos que, como escrevi em Power in movement, a maioria dos ciclos começa basicamente da mesma forma, eles terminam de maneiras muito diferentes, dependendo da interação dos movimentos, o estado e os contramovimentos. No Egito, já houve um declínio das forças seculares que iniciaram a revolução e a ascensão de partidos muçulmanos muito mais conservadores. No que diz respeito à abordagem dos Novos Movimentos Sociais, isto depende de como você o interpreta. Originalmente, a teoria foi desenvolvida para entender os assim chamados movimentos "pós-materialistas" nos países mais avançados da Europa, e então ela foi estendida (inapropriadamente, a meu ver) à América Latina e a outros países do Sul, sem um entendimento claro de que os fundamentos estruturais e os processos políticos dessas regiões eram muito diferentes dos da região em que a teoria nasceu. Em parte, isso se deveu às complexidades da situação latino-americana nas décadas de 1980 e 1990, mas minha impressão é que isso também se deveu ao desejo - por parte de estudiosos que queriam seguir os teóricos europeus dos Novos Movimentos Sociais, como Touraine - de generalizar a teoria para além das condições estruturais a partir das quais ela se originou.

A.A. \& A.B. Na sua opinião, como a abordagem da política confrontacional vem contribuindo para os debates sobre teoria social, principalmente no que diz respeito ao dilema ação-estrutura?

S.T. Essa pergunta é grande demais para uma entrevista breve, e não sou a pessoa ideal para respondê-la. O que posso dizer é que, no programa de pesquisa da política confrontacional, McAdam, Tilly e eu decidimos evitar esse debate em nossa discussão sobre os mecanismos e processos que conectam estrutura e ação. Assim, nossa análise da revolução bem-sucedida na Nicarágua, comparada com a revolta fracassada de 1989 na Praça da Paz Celestial, se con- 
centrou no mecanismo da deserção das elites, que vinculou a situação estrutural de autoritarismo à ação bem-sucedida do movimento sandinista. De maneira semelhante, quando analisamos confrontação transnacional, voltamos nosso foco para o processo de mudança de escala, composto de vários mecanismos de difusão. O que não conseguimos fazer foi explicar o tipo de metodologia que permitiria aos estudiosos proceder a um exame sistemático destes mecanismos e processos, algo que tentamos incentivar recentemente numa edição especial da revista Mobilization, com a ajuda de um grupo de estudiosos trabalhando na Europa e nos Estados Unidos com episódios de mobilização.

A.A. \& A.B. Desde a morte de Charles Tilly, muitos de seus antigos alunos e colegas, incluindo você, vêm fazendo uma avaliação do legado dele. Até mesmo um handbook sobre a obra de Tilly está sendo elaborado. Qual é o status que você atribui a Tilly na sociologia e, mais especificamente, nos campos das sociologias política e histórica e da sociologia comparativa?

S.T. Eu escrevi um dos capítulos para o handbook em inglês (que, infelizmente, ninguém poderá comprar porque custará mais de 100 dólares!), e McAdam e eu contribuímos com um artigo para outro livro que está sendo publicado na Espanha e que foi organizado por Maria Jesus Funes (2011). Para mim, a maior contribuição de Tilly foi vincular sua grande inovação metodológica - a análise disciplinada e qualitativa de eventos confrontacionais - à teoria histórica/ antropológica do desenvolvimento do repertório confrontacional. Isto, é claro, deixa de fora muitas das suas outras contribuições (o estudo da guerra, por exemplo, e da formação de estados nacionais, das desigualdades sociais e da sociologia urbana). Mas considero a primeira contribuição mencionada como a mais original, porque mostra como inovações teóricas e metodológicas podem ser intimamente fundidas. Se eu fosse me queixar (e reclamei disso a Tilly até pouco antes de seu falecimento), eu reclamaria do fato de ele nunca ter relacionado sua compreensão dos confrontos com seu trabalho sobre guerra e formação de estados nacionais. Como tributo final a Tilly, estou tentando combinar essas duas perspectivas no livro que estou escrevendo agora sobre "guerra, direitos e confronto", que começará com a Revolução Francesa, no melhor estilo tillyano.

A.A. \& A.B. Você se aposentou recentemente. Como avalia sua própria produção intelectual ao longo de sua carreira? E quais são seus planos? Você está trabalhando num livro novo?

S.T. Outra pergunta difícil. Tive que lidar com esta questão quando escrevi meu novo livro Strangers at the gates (Tarrow, 2012). Após ter publicado tantos livros e artigos ao longo de 50 anos, é um tanto embaraçoso medir o próprio sucesso em termos de sua produção acadêmica. Creio que minha maior contribuição foi para os meus alunos, muitos dos quais têm demonstrado sua gratidão ao produzirem trabalhos maravilhosos recentemente. Qual é a minha contribuição 
substancial? Nada me parece mais cansativo do que a estreiteza e o sectarismo que se infiltraram em nossos estudos sobre a política confrontacional. Se for pressionado a identificar aquilo que considero ser minha maior contribuição acadêmica, diria que tem sido a de ser um sintetizador de teorias e descobertas feitas na Europa e nas Américas, na Sociologia e na Ciência Política e entre as tradições de pesquisa quantitativa e contextualizada nas ciências sociais.

A.A. \& A.B. Quais sugestões de pesquisa você daria aos estudantes brasileiros nas áreas da sociologia histórica ou da sociologia política? ${ }^{4}$

S.T. Não creio que eu seja qualificado para responder a esta pergunta, já que, como eu disse, sou adepto da ciência social contextualizada, e a única visita que fiz ao Brasil não foi o suficiente para me passar uma ideia do contexto político e científico brasileiro. Convidem-me para voltar ao Brasil e tentarei dar uma resposta melhor!

Entrevista concedida em 5 de dezembro de 2011.

Angela Alonso, doutora em Sociologia pela Universidade de São Paulo (USP), com pós-doutorado pela Universidade de Yale, é professora do Departamento de Sociologia da USP, pesquisadora do Centro Brasileiro de Análise e Planejamento (Cebrap) e bolsista de Produtividade em Pesquisa do Conselho Nacional de Desenvolvimento Científico e Tecnológico (CNPq). Tem se valido da perspectiva tillyana em seus trabalhos nas áreas de sociologia política e histórica, desde Ideias em movimento: a geração 1870 na crise do Brasil-Império (2002), em artigos sobre o movimento ambientalista contemporâneo e sobre os movimentos políticointelectuais oitocentistas, bem como em sua pesquisa atual sobre o movimento pela abolição da escravidão no Brasil.

André Botelho é professor do Departamento de Sociologia da Universidade Federal do Rio de Janeiro (UFRJ) e um dos editores de Sociologia \& Antropologia. Desenvolve atualmente, com o apoio do Conselho Nacional de Desenvolvimento Científico e Tecnológico (CNPq) e da Fundação de Amparo à Pesquisa do Estado do Rio de Janeiro (Faperj), projetos de pesquisa sobre teoria e história na sociologia política no Brasil. Alguns dos seus trabalhos nessa direção são: "Political Sociology", publicado na Sociopedia.ISA (2011), "Sequências de uma sociologia política brasileira" (2007); "Passagens para o Estado-nação: a tese de Costa Pinto" (2009); e "Público e privado no pensamento social brasileiro" (2011). 


\section{NOTAS}

1 No Brasil só foram publicados, até o momento, um livro de Charles Tilly, Coerção, capital e estados europeus, 1990-1992 (São Paulo: Edusp, 1996), e um de Sidney Tarrow, O poder em movimento: movimentos sociais e confronto político (Petrópolis: Vozes, 2009).

2 Ver, ainda, os artigos de Angela Alonso e de Breno Bringel nesta edição de Sociologia \& Antropologia.

3 Ver resenha do livro nesta edição de Sociologia \& Antropologia.

4 Tarrow esteve no Brasil no I Seminário Internacional (III Seminário Nacional) "Movimentos Sociais, Participação e Democracia”, realizado na Universidade Federal de Santa Catarina. A conferência que proferiu na ocasião, "Global, conventional and warring movements and the suppression of contention: themes in contentious politics research", foi publicada em Política e Sociedade, 2011, 10/18, p. 25-49.

\section{REFERÊNCIAS BIBLIOGRÁFICAS}

Funes, Maria Jesus (org.). A proposito de Tilly: conflicto, poder y acción colectiva. Madri: Centro de Investigaciones Sociológicas, 2011.

Tarrow, Sidney. Peasant communism in Italy. New Haven: Yale University Press, 1967.

Strangers at the gate: movements and state in contentious politics. Cambridge: Cambridge University Press, 2012. 


\section{Palavras-chave: Resumo:}

Sidney Tarrow; Charles

Tilly; Ação coletiva;

Confrontos políticos;

Sociologia histórica.

Keywords:

Sidney Tarrow; Charles Tilly; Collective action; Political confrontations;

Historical sociology.
Nesta entrevista Sidney Tarrow fala sobre a importância de Charles Tilly e de sua sociologia histórica da ação coletiva. Lembra de sua parceria com Tilly e discute aspectos centrais do seu próprio trabalho em curso sobre o confronto político. Com esta entrevista, Sociologia \& Antropologia procura contribuir para o esclarecimento da relação entre o legado de Charles Tilly e a sociologia da ação coletiva no Brasil.

\section{Abstract:}

In this interview Sidney Tarrow talks about the importance of Charles Tilly's historical sociology of collective action. Tarrow remembers his collaboration with Tilly and singles out central aspects of his own research on contentious politics. With this interview, Sociologia \& Antropologia seeks to give insight into the interplay between Charles Tilly's legacy and the sociology of collective action in Brazil. 